\title{
MORPHOLOGY OF THE ANTERIOR CLINOID PROCESS IN A SELECT KENYAN POPULATION
}

\author{
William Sibuor, Isaac Cheruiyot, Jeremiah Munguti, James Kigera, Gichambira Gikenye \\ Correspondence to William Sibuor, Department of Human Anatomy, University of Nairobi. P.O. Box \\ 30197-00100, Nairobi, Kenya. Email: williamsibuor@gmail.com
}

\begin{abstract}
Knowledge of the morphological variations of the anterior clinoid process is pertinent during anterior clinoidectomy to prevent injury to the adjacent neurovascular structures as well as in the interpretation of skull base radiographs. Fifty-one open crania (102 anterior clinoid processes) were obtained from the Departments of Human Anatomy in three Kenyan Universities. Caroticoclinoid foramen was present in nine (17.6\%) out of the 51 skulls studied. Of the 9 skulls, 2 had bilateral complete foramina while the remaining 7 had unilateral foramina, all on the left side. The mean length of the anterior clinoid process ranged between 5.0 and $18.8 \mathrm{~mm}$ with a mean of $10.92 \pm 2.79$ $\mathrm{mm}$. The mean width was found to be $10.43 \pm 2.67 \mathrm{~mm}$ (range: $5.3-18.0 \mathrm{~mm}$ ) while the average thickness was $5.43 \pm 2.02 \mathrm{~mm}$ (range: $1.3-11.9 \mathrm{~mm}$ ). There were no statistically significant side differences in the dimensions of the anterior clinoid process. Type IIIb anterior clinoid process was the commonest (47.1\%) while type IIIa was the least common (7.8\%). Compared to other populations, the anterior clinoid process in our setting shows some differences involving its type and the caroticoclinoid foramen. These features should be taken into account when interpreting skull base radiographs and planning for anterior clinoidectomies.
\end{abstract}

Key words: Clinoid Process, Kenya, Morphology.

The anterior clinoid process (ACP) is a bony projection on the posterior border of the lesser wing of sphenoid (Hunargi et al., 2008). It is related medially to the optic nerve, inferolaterally to the oculomotor nerve and inferomedially to the internal carotid artery (ICA) and its ophthalmic branch (Lehmberg et al., 2014). These structures may be injured during anterior clinoidectomy (Lee et al., 2013) and the injuries can be attributed partly to the varied morphology of ACP (Giannota, 2002; Aragao et al., 2013). Furthermore, the ACP is connected to the middle clinoid process by the caroticoclinoid ligament (CCL) which may ossify, contributing to the formation of a caroticoclinoid foramen (Standring, 2008). This ossified ligament may complicate anterior clinoidectomy (Yang et al., 2006; Kapur and Mehic, 2012). Knowledge of the variations in morphology of the ACP is therefore important to minimize such iatrogenic injuries.
The morphology of the ACP shows significant population-specific variations in its dimensions and prevalence of caroticoclinoid foramen (Lee et al., 1997; Gupta et al., 2005; Desai and Spreepadma, 2010; Akture and Baskaya, 2014; da Costa et al., 2016). The dimensions are used to determine the types of ACP. The types influence the choice of surgical technique employed during anterior clinoidectomy (Cecen et al., 2016). There is however paucity of data in the African populations and lacking all together among Kenyans. This study therefore sets out to describe the conventional and variant morphology of the ACP in a Kenyan population, with regards to its length, width, thickness and presence of caroticoclinoid foramen.

\section{METHODS}

A total of fifty-one skulls $(n=102$ ACP) of unidentified gender were obtained from the Human Anatomy laboratories of the University of Nairobi, Jomo Kenyatta University of Agriculture and Technology and Mount Kenya University. Skulls with erupted third molars 
and without any obvious deformations in the paraclinoid region were selected. The ACP was identified in the middle cranial fossa. The skulls were observed for the presence of CCF. The basal length and width of the ACP were measured using a pair of sliding Vernier calipers (Sealey Professional Tools TM), accurate to $0.1 \mathrm{~mm}$. The length was measured from the base to its tip while the width was measured at the base (Figure 1). These referenced points were based on a study by Souza et al., 2016. The thickness was measured using a pair of adjustable compasses with a ruler. All the measurements were recorded in millimeters. The ACP was classified into four types based on the dimensions using a modification of the criteria given by Cecen et al., (2016). The classification is as follows: Type I- short $(<10.5 \mathrm{~mm})$ and wide $(>8.14 \mathrm{~mm})$, type II long $(>10.5 \mathrm{~mm})$ and narrow $(<8.14 \mathrm{~mm})$, type IIIa short $(<10.5)$ and narrow $(<8.14)$, type IIIb long ( $>10.5)$ and wide (>8.14). The data was collected by a single observer and each measurement taken thrice and arithmetic average taken to minimize the intra-observer bias. Data analysis was performed using SPSS version 21.1 (SPSS IBM). Means, standard deviations and range were obtained. The paired Student's t test was used to determine the statistically significant differences in means between the right and left ACP. $\mathrm{P} \leq 0.05$ was considered statistically significant at $95 \%$ confidence interval.

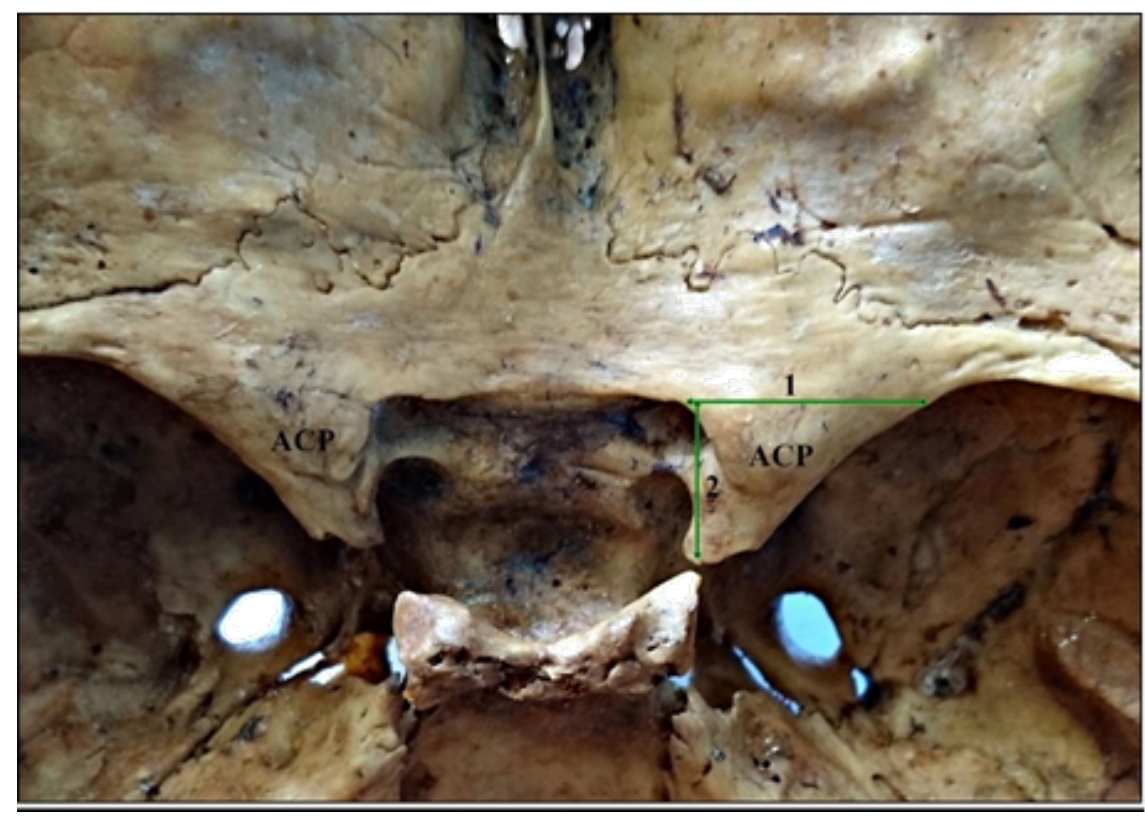

Figure 1: Measurements taken on the anterior clinoid process (1- basal width, 2-length, ACP- anterior clinoid process).

Presence of CCF: Nine (17.6\%) out of the 51 skulls studied had a complete CCF. Of the 9 skulls, 2 had bilateral complete CCF while the remaining 7 had unilateral left complete CCF (Figure 2). Dimensions of the ACP: The mean length of the ACP was $10.92 \pm 2.79 \mathrm{~mm}$ (range: $5.0-18.8 \mathrm{~mm}$ ). The mean width was $10.43 \pm 2.67 \mathrm{~mm}$ (range: $5.3-18.0 \mathrm{~mm}$ ) while the average thickness was $5.43 \pm 2.02 \mathrm{~mm}$ (range: $1.3-11.9 \mathrm{~mm}$ ). There were no statistically significant side differences in the dimensions of the ACP (Table 1).

Types of Anterior Clinoid Process: The most common type of ACP was type IIIb seen in $48(47.1 \%)$ ACPs while type IIIa had the lowest prevalence and was seen in only 8 $(7.8 \%)$ ACPs. This is summarized in the pie chart below (figure 3). 


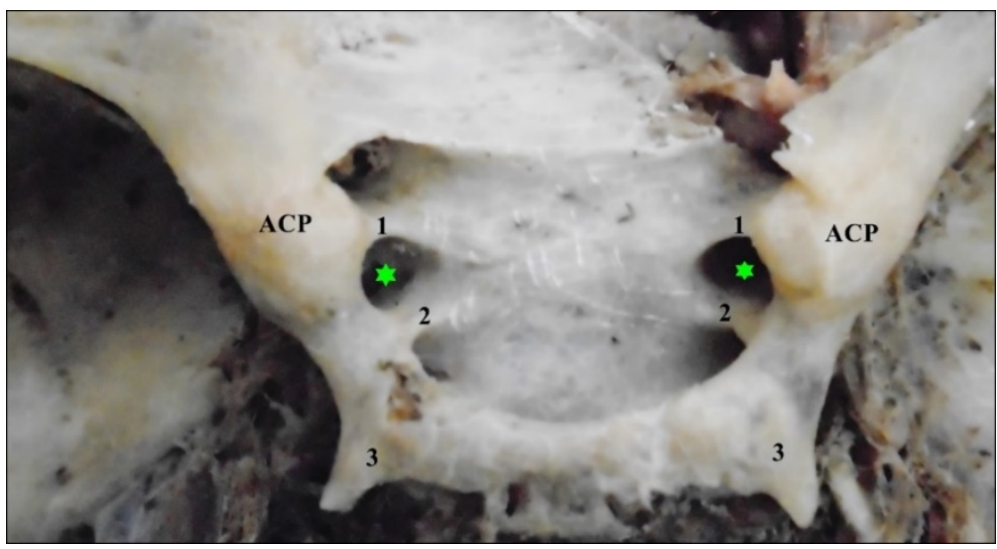

Figure 2: Bilateral complete caroticoclinoid foramen indicated by the green asterisks (1- optic strut, 2- ossified caroticoclinoid ligament, 3- posterior clinoid process, ACP- anterior clinoid process).

Table 1: Side differences in the dimensions of anterior clinoid process

\begin{tabular}{|l|l|l|l|}
\hline \multirow{2}{*}{ Dimensions $(\mathrm{mm})$} & \multicolumn{2}{|l|}{ Mean \pm SD } & P-value \\
\cline { 2 - 3 } & Left & Right & \\
\hline Length & $\mathbf{1 0 . 7 2} \pm \mathbf{2 . 7 7}$ & $\mathbf{1 1 . 1 2} \pm \mathbf{2 . 8 3}$ & $\mathbf{0 . 1 8 4}$ \\
\hline Width & $\mathbf{1 0 . 3 4 \pm 2 . 6 9}$ & $\mathbf{1 0 . 5 2} \pm \mathbf{2 . 6 8}$ & $\mathbf{0 . 6 8 6}$ \\
\hline Thickness & $\mathbf{5 . 4 7} \pm \mathbf{1 . 9 5}$ & $\mathbf{5 . 3 8} \pm \mathbf{2 . 1 1}$ & $\mathbf{0 . 6 4 6}$ \\
\hline
\end{tabular}

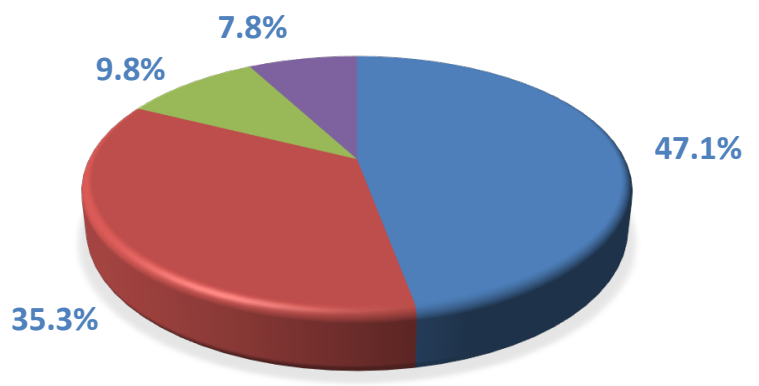

Figure 3: Pie chart showing the prevalence of the types of anterior clinoid process.

\section{DISCUSSION}

Knowledge of the variant anatomy of the ACP is important in preventing iatrogenic injuries to closely related neurovascular structures during anterior clinoidectomy for procedures involving internal carotid artery aneurysms and skull base tumors.

In the present study, the CCF was found in $17.6 \%$ of the studied population. This prevalence was comparable to those reported in other populations (Table 2) such as Nepalese (Gupta et al., 2005) and European (Kapur and Mehic, 2012). The prevalence was however higher than that reported among Brazilians (Freire et al., 2011) and lower than found in the Indian population (Desai and
Spreepadma, 2010). All the unilateral CCF in our population were on the left. This is a unique finding compared to other populations in which the right side was more common (Gupta et al., 2005; Freire et al., 2011; Kapur and Mehic, 2012) or no side difference existed (Desai and Spreepadma, 2010). All these studies were conducted in different ethnic groups suggesting a racial difference in the ACP morphology. The variations could also be due to population differences in epigenetic influences. For instance, Carolineberry, (1967) documented morphological variations of the cranium which she reported to be under epigenetic influence and to vary among different populations. Some of the variations 
observed involved the sphenoid bone, of which the ACP and middle clinoid processes are part. It is therefore plausible that population differences in epigenetic influences may have contributed to the observed variations in the prevalence of CCF.

In about $17 \%$ of the studied population, the ossified ligament forming the CCF forms an extra fixation point for the ACP. Failure to recognize it during anterior clinoidectomy results in incomplete mobilization of the ACP and hence inappropriate retraction of the ICA. This may lead to ICA rupture with fatal outcome (Kapur and Mehic, 2012; Aragao et al., 2013). The CCF may also be misinterpreted as an accessory optic canal and this may thus make the differentiation of structures via standard radiography and CT difficult (Zdilla et al., 2015).

Given that the CCF is a fairly common feature in our population, it calls for prudence during interpretation of skull base radiographs and during anterior clinoidectomies to avoid the associated complications.

The length, width and thickness of the ACP obtained from this study are largely comparable with other populations. The length was comparable to that of the Indian (Hunnargi et al., 2008), European (Kapur and Mehic, 2012), Brazilian (da Costa et al., 2016) and Nepalese (Gupta et al., 2005) populations but longer than in the Korean population (Lee et al., 1997). On the other hand, the average width of the ACP was comparable to the Nepalese, European and Korean populations. It was however wider than the Brazilian and narrower than the Indian population. The thickness of ACP was comparable to that of the Nepalese and Korean population but smaller than that of the Indian population (Table 3). The observed variations in the dimensions of ACP could be due to methodological, racial or genetic factors.

The length and width of ACP influence its type which influences the surgical techniques applied during anterior clinoidectomies (Cecen et al., 2016). Based on our modification of the criteria by Cecen et al., (2016), most of the ACP in our population were type IIIb (long and wide). This is comparable to the findings of Cecen et al., 2016 on a Brazilian population in which type III ACPs in general were the commonest (65.7\%).

Table 2: Comparison of the prevalence of caroticoclinoid foramen among different populations

\begin{tabular}{|l|l|l|l|}
\hline Study & Population & Sample size & Percentage \\
\hline Gupta et al., 2005 & Nepalese & 35 & $20.00 \%$ \\
\hline $\begin{array}{l}\text { Desai and } \\
\text { Spreepadma, 2010 }\end{array}$ & Indian & 223 & $37.19 \%$ \\
\hline Freire et al., 2011 & Brazilian & 80 & $8.50 \%$ \\
\hline $\begin{array}{l}\text { Kapur and } \\
\text { Mehic, 2012 }\end{array}$ & European & 200 & $16.75 \%$ \\
\hline $\begin{array}{l}\text { Da Costa et al., } \\
2016\end{array}$ & Brazilian & 597 & $14.20 \%$ \\
\hline Current study & Kenyan & 51 & $17.60 \%$ \\
\hline
\end{tabular}

Table 3: Comparison of the anterior clinoid process dimensions with other populations

\begin{tabular}{|l|l|l|l|l|l|}
\hline Study & Population & Length & Width & Thickness & Methodology \\
\hline $\begin{array}{l}\text { Lee et al., } \\
1997\end{array}$ & Korean & $9.18 \pm 1.55$ & $9.63 \pm 1.49$ & $5.32 \pm 1.07$ & $\begin{array}{l}\text { Dry bone } \\
\text { Measurement }\end{array}$ \\
\hline $\begin{array}{l}\text { Gupta et al., } \\
2005\end{array}$ & Nepalese & $10.74 \pm 2.37$ & $10.83 \pm 1.20$ & $5.13 \pm 1.03$ & $\begin{array}{l}\text { Dry bone } \\
\text { measurement }\end{array}$ \\
\hline $\begin{array}{l}\text { Hunnargi et } \\
\text { al., 2008 }\end{array}$ & Indian & $10.68 \pm 1.90$ & $12.40 \pm 2.58$ & $6.88 \pm 1.09$ & $\begin{array}{l}\text { Dry bone } \\
\text { measurement }\end{array}$ \\
\hline $\begin{array}{l}\text { Kapur and } \\
\text { Mehic, 2012 }\end{array}$ & European & $9.90 \pm 1.60$ & $9.40 \pm 1.40$ & - & $\begin{array}{l}\text { Dry bone } \\
\text { Measurement }\end{array}$ \\
\hline da Costa et & Brazilian & $10.31 \pm 2.10$ & $7.70 \pm 1.73$ & - & Ct Scans \\
\hline
\end{tabular}




\begin{tabular}{|l|l|l|l|l|l|}
\hline al., 2016 & & & & \\
\hline Current study & Kenyan & $10.92 \pm 2.79$ & $10.43 \pm 2.67$ & $5.43 \pm 2.02$ & $\begin{array}{l}\text { Dry bone } \\
\text { measurement }\end{array}$ \\
\hline
\end{tabular}

The clinoid space is the space exposed after anterior clinoidectomy (Rajasekhar and Bhattacharyya, 2007) and its dimensions vary with the dimensions of the ACP (Freire et al., 2011). Type IIIb ACPs may thus provide a greater exposure of the clinoid space (Sade et al., 2005). However, owing to their length and width, these type IIIb ACPs have greater bone volumes to be drilled out. These may require more extensive drilling during anterior clinoidectomy and hence the need of the surgeon to take it into consideration.

In conclusion, the anterior clinoid process in our setting shows some differences involving the caoticoclinoid formamen and the type of anterior clinoid process. These features should be taken into account when interpreting skull base radiographs and planning for anterior clinoidectomies.

ACKNOWLEDGEMENT: The authors would like to acknowledge Mr. Robert Wanyama and Mr. Koech of the Departments of Human Anatomy, Mount Kenya University and Jomo Kenyatta University of Agriculture and Technology respectively for their technical support during the collection of data for the study.

\section{REFERENCES}

1. Akture, E., Baskaya, M., 2014. Microsurgical anatomy and variations of the anterior clinoid process. Turkish; 24: 484-493.

2. Aragao, J., Fontes, L., de Aragao, J., Reis, F., 2013. Ossification of interclinoid ligaments and their clinical importance. International Journal of Anatomical Variations, 6: 201-202.

3. Carolineberry, A., Berry, R., 1967. Epigenetic variation in the human cranium. Journal of Anatomy, 101: 361-367.

4. Cecen, A., Celikoglu, E., Kale, A., Eroglu, B., 2016. Pre-operative measurement of the morphometry and angles of the anterior clinoid process (ACP) for aneurysm surgery. International Journal of Morphology, 34: 1333-1338.

5. da Costa, M., de Oliveira Santos, B., de Araujo Paz, D., Rodrigues, T., Abdala, N., Centeno, R., Cavalheiro, S., Lawton, M., Chaddad-Neto, F., 2016. Anatomical variations of the anterior clinoid process: A Study of 597 Skull Base Computerized Tomography Scans. Operative Neurosurgery, 12: 289-297.

6. Desai, S., Sreepadma, S., 2010. Study of caroticoclinoid foramen in dry human skulls of North Interior Karnataka. National Journal of Basic Medical Sciences, 1: 60-64.

7. Freire, A., Rossi, A., Prado, F., Groppo, F., Ferreira-Caria, P., Botacin, P., 2011. Caroticoclinoid foramen in human skulls: incidence, morphometry and its clinical implications. International Journal of Morphology, 29: 427-431.

8. Giannotta, S., 2002. Ophthalmic segment aneurysm surgery. Neurosurgery, 50: 558-562.

9. Gupta, N., Ray, B., Ghosh, S., 2005. A study on anterior clinoid process and optic strut with emphasis on variations of caroticoclinoid foramen. Nepal Medical College Journal; 7: 141144.

10. Hunnargi, S., Ray, B., Pai, S. Siddaraju, K., 2008. Metrical and non-metrical study of anterior clinoid process in South Indian adult skulls. Surgical and Radiologic Anatomy, 30: 423-428.

11. Kapur, E., Mehić, A., 2012. Anatomical variations and morphometric study of the optic strut and the anterior clinoid process. Bosnian Journal of Basic Medical Sciences, 12: 88-93.

12. Lee, H., Chung, I., Choi, B., Lee, K., 1997. Anterior clinoid process and optic strut in Koreans. Yonsei Medical Journal; 38: 151-154.

13. Lee, H., Park, H., Yoo, K., Kim, K., Song, Y., 2013. Measurement of critical structures around paraclinoidal area: a cadaveric morphometric study. Journal of Korean Neurosurgical Society, 54: $14-18$.

14. Lehmberg, J., Krieg, S., Meyer, B., 2014. Anterior clinoidectomy. Acta Neurochirurgica; 156: 
415-419.

15. Rajasekhar, V., Bhattacharyya, K., 2007. Progress in clinical neurosciences. Volume 2. Delhi: Byword Books, 250.

16. Sade, B., Kweon, C., Evans, J., Lee, J., 2005. Enhanced exposure of carotico-oculomotor triangle following extradural anterior clinoidectomy: A comparative anatomical study. Skull Base; 15: 157-161.

17. Souza, A., Ankolekar, V., Nayak, N., Hosapatna, Souza, A., 2016. Morphometric study of anterior clinoid process and optic strut and the ossification of carotico-clinoid ligament with their clinical importance. Journal of Clinical and Diagnostic Research. 10: AC05-AC07.

18. Standring, S., 2008. Gray's Anatomy: the anatomical basis of clinical practice. 40th edition, Edinburgh: Churchill Livingstone, 423-424.

19. Yang, Y., Wang, H., Shao, Y., Wei, Z., Zhu, S., Wang, J., 2006. Extradural anterior clinoidectomy as an alternative approach for optic nerve decompression: anatomic study and clinical experience. Neurosurgery, 59: ONS-253.

20. Zdilla, M., Cyrus, L., Lambert, H., 2015. Carotico-clinoid foramina and a double optic canal: A case report with neurosurgical implications. Surgical Neurology International; 6:13. 